\title{
Effects of Different Visual Class on Agility in the Visually Impaired Soccer Players
}

\author{
HIROFUMI MAEHANA*1), YUKI IGUCHI*1), TAKUMI HORIIKE*2), \\ KENICHI KOSHIYAMA*3), MASAFUMI YOSHIMURA*1) \\ *1) Graduate School of Health and Sports Science, Juntendo University, Chiba, Japan, *2) Faculty of Health and Sports \\ Science, Juntendo University, Chiba, Japan, *3) Department of Team Coaching, Iwamizawa Campus, Hokkaido University of \\ Education, Hokkaido, Japan
}

\begin{abstract}
The purpose of the present study was to get the reference value of agility of visually impaired soccer players in accordance with the blind class. Twenty one male visually impaired soccer players (B1: $n=12, B 2: n=4, B 3: n=5)$ and twelve male university soccer players participated in this study voluntarily. Subjects' height, body weight, body mass index, body fat percentage. The agility performance at side step test was evaluated by using two support rope. The kind of the support rope was 3 fulcrums support rope (the weight mobility type $=$ WMT) and 1 fulcrum support rope in (the pendulum mobility type =PMT). The results of there were no difference on the blind class by used WMT method in the side-step test. But there was a difference on the blind class by used PMT method in the side-step test $(p>0.05)$. Sighted subjects were higher recorded by used PMT method in blindfold $(p>0.05)$. In conclusion, the findings of the present study indicated the reference value of agility ability of each of the blind class. Suggested that they had been relationship in ability to recognize the space involved with pendulum mobility operation. Low vision was suggested that the superior agility performance with spatial perception than blind.
\end{abstract}

Key words: agility performance, visually impaired, blind class, blind, low vision, spatial perception

\section{Introduction}

Agility is generally defined as the ability to change direction of the body rapidly, without losing balance, using a combination of strength, power, and neuromuscular coordination ${ }^{1-3)}$. Thus, agility is very important in soccer, and the ability of soccer players to produce fast paced variable actions is known to impact soccer performance ${ }^{4)}$ 5).

Visually impaired of physical strength is low as compared with the sighted people, especially low agility. Suggested that visually impaired has few opportunities to experience a whole body movement, including the jumping behavior ${ }^{6)}$. In addition, blindness can cause low physical work capacity, posture problems, orientation difficulties, balance problems. Previous studies include information about these disturbances ${ }^{7-9)}$.
In Paralympic sport Football $5^{-} \mathrm{a}^{-}$side is a game played by athletes with visually impaired and is known worldwide as blind football or blind soccer. This sport had its first national Championship in Spain, in 1986, and first appeared in the Paralympic Games in Athens in $2004^{10)}$. The athletes can be categorized in three levels: B1 (from no light perception in either eye up to light perception, unable to recognize the shape of a hand at any distance or direction); B2 (from ability to recognize the shape of a hand up to a visual acuity of $20 / 600$ or a visual field of less than $5^{\circ}$ in the best eye with the best practical eye correction); B3 (from visual acuity above $20 / 600-20 / 200$ or a visual field of less than $20^{\circ}$ and more than $5^{\circ}$ in the best eye with the best correction) ${ }^{11)}$. In football 5 -a-side, only B1 athletes can compete.

Side-step test is generally used in the test to

Corresponding author: Hirofumi Maehana

Graduate School of Health and Sports Science, Juntendo University

1-1 Hirakagakuendai, Inzai-shi, Chiba 270-1695, Japan

TEL: + 81-476-98-1001 (ext. 412) FAX: +81-476-98-1011 E-mail: sh4214012@juntendo.ac.jp

The $2{ }^{\text {nd }}$ Congress, International Academy of Sportology 〔Held on Sep. 12, 2015〕

[Received Dec. 18, 2015] 
measure the agility. However, in the test that has been developed for the sighted people, there is a possibility to evaluate lower the agility of the visually impaired ${ }^{12)}$. For the visually impaired, in order to adjust the measurement conditions, support rope has been attempted. By using the support ropes, it has been suggested that can accurately measure the agility of the visually impaired ${ }^{13)}$. However, there may be characterized in agility depending on the blind class. Investigate the agility ability to another failure class, it is important to report the characteristics of agility in the visually impaired. The purpose of the present study was to get the reference value of agility of visually impaired soccer players in accordance with the blind class.

\section{Methods}

\section{Subjects}

Twenty one male visually impaired soccer players (B1: $n=12, B 2: n=4, B 3: n=5)$ and twelve male university soccer players (sighted subjects) participated in this study voluntarily. The causes of impaired sight were a congenital disorder in sixteen subjects, an acquired disorder in five subjects. Their mean age, height, body mass and body fat were B1: $24.4 \pm 5.6 \mathrm{yrs}, 171.1 \pm 4.8 \mathrm{~cm}, 65.0 \pm$ $8.0 \mathrm{~kg}$ and $13.8 \pm 4.3 \%, \mathrm{~B} 2: 25.7 \pm 4.1 \mathrm{yrs}, 171.2$ $\pm 4.0 \mathrm{~cm}, 64.8 \pm 4.6 \mathrm{~kg}$ and $12.5 \pm 1.2 \%, \mathrm{~B} 3: 19.8$ $\pm 0.9 \mathrm{yrs}, 171.0 \pm 6.0 \mathrm{~cm}, 65.5 \pm 5.7 \mathrm{~kg}$ and 12.2 $\pm 1.9 \%$ respectively. The study group consisted of active blind football players of the blind football team and all the players were trained for two hours three days per week. Subjects' mean training

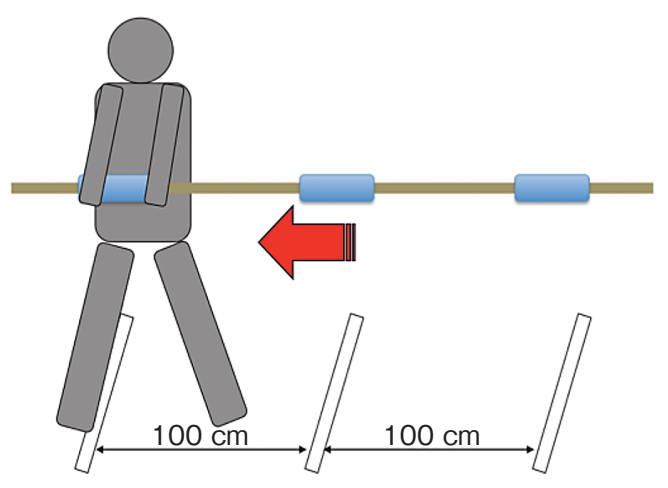

Figure-1 3 fulcrums support rope (the weight mobility type $=$ WMT) experience was $2.3 \pm 2.5$ yrs. Subjects were informed about the possible risks and benefits of the study and gave informed consent to participate in this study.

\section{Agility performance evaluation (side-step test)}

The agility performance of the visually impaired soccer players and university soccer players were evaluated using side-step tests: the weight mobility type (WMT) and the pendulum mobility type (PMT). The number of times was recorded using electronic timing gates (Fusion Sport Smart Speed, Wales, UK) located at the 3 lines. Subjects stood at a center line, then moved $100 \mathrm{~cm}$ to the side and touched a line with the closest foot, moved back to the center then jumps $100 \mathrm{~cm}$ to the other side, then back to the center. This is one complete cycle. The subjects tried to complete as many cycles as possible in 20 seconds. These tests were performed in an indoor court to eliminate environmental conditions, and visual conditions were the same by using a blindfold. Side-step test each performed twice to measure the good recording.

\section{Support rope}

Two types of support rope were used in the side-step test. The kind of the support rope was 3 fulcrums support rope (the weight mobility type $=$ WMT) and 1 fulcrum support rope (the pendulum mobility type $=$ PMT). WMT method is the way to move the center of gravity of the body to each fulcrum (Figure-1). PMT method is the way to move while fixing the center of gravity of the body on a central fulcrum (Figure-2). Thus, side-step test was conducted respectively with the two

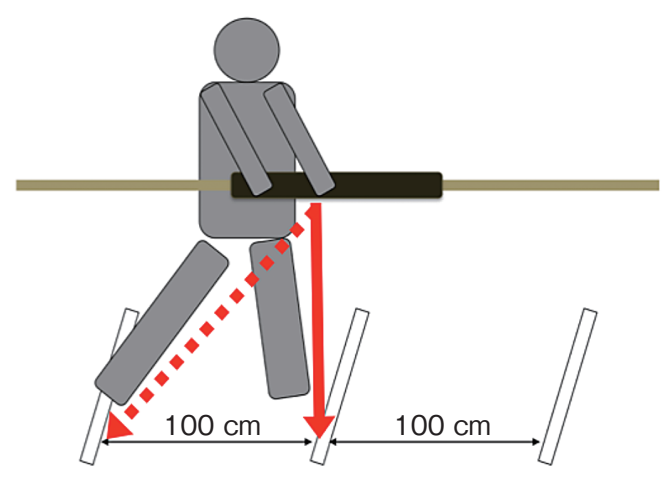

Figure-2 1 fulcrum support rope (the pendulum mobility type $=$ PMT) 
moving method.

\section{Statistical analyses}

B2 and B3 play a game as "low vision soccer" together at the statistics it was with the same group. The data are reported as means and standard deviations. Repeated-measures ANOVA was used to compare the WMT and PMT performance both within (B1 vs B2 $\cdot$ B3 vs Univ) and between the two experimental method (WMT vs PMT) used independent t-test. Then, the relationships between WMT and PMT were evaluated by the Pearson Product Moment Correlation analysis. All analyses were executed in SPSS for Windows version 10.0 and the statistical significance was set at $\mathrm{p}<0.05$.

\section{Results}

\section{WMT method (3 fulcrums support rope)}

Record of side-step test by WMT was as follows, B1: $54 \pm 7$, B2 $\cdot$ B3: $56 \pm 3$ and Univ: $47 \pm 4$, respectively (Figure-3). Comparison of each group in side-step test by WMT, B2 $\cdot$ B3 was significantly higher than Univ $(\mathrm{p}<0.05)$. There was no significant difference in $\mathrm{B} 1$ and $\mathrm{B} 2 \cdot \mathrm{B} 3$ within of the WMT method.

\section{PMT method (1 fulcrum support rope)}

Record of side-step test by PMT was as follows, B1: $44 \pm 6, \mathrm{~B} 2 \cdot \mathrm{B} 3: 51 \pm 3$ and Univ: $65 \pm 6$, respectively (Figure-4). Comparison of each group in side-step test by PMT, B2 - B3 was significantly higher than B1 $(p<0.05)$, Univ was significantly higher than B1 and B2 $\cdot$ B3 $(p<0.05)$.

\section{Comparison of WMT and PMT}

$\mathrm{B} 1$ and B2 $\cdot$ B3 together towards WMT was high recording than PMT, there were a significant difference between the method of only B1 $(p<$ $0.05)$. In sighted subjects, the visually impaired was the opposite result (Figure-5). In Univ subjects was higher PMT than WMT, there were a significant difference between the method $(\mathrm{p}<$ $0.05)$.

\section{Relationship between WMT and PMT}

The correlation between the method of WMT and PMT, B1 $(n=12): r=0.5, B 2 \cdot B 3(n=9): r=$
0.2 , Univ $(n=12): r=0.01$, respectively. There was no significant relationship of both methods.

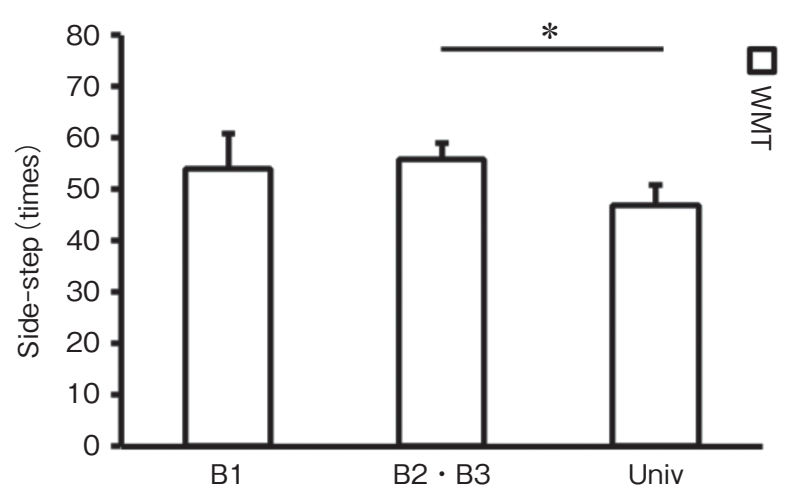

Figure-3 Comparison of side step test in WMT method *Significant difference $(\mathrm{p}<0.05)$.

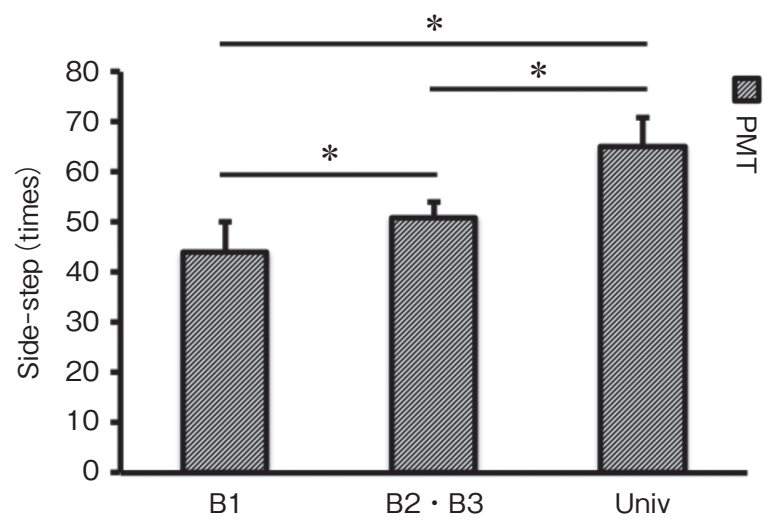

Figure-4 Comparison of side step test in PMT method ${ }^{*}$ Significant difference $(\mathrm{p}<0.05)$.

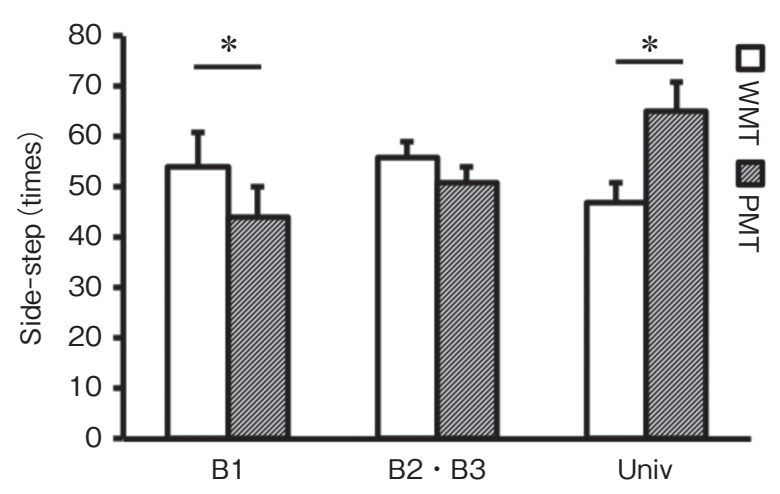

Figure-5 Comparison of side step test in WMT method and PMT method

* Significant difference $(\mathrm{p}<0.05)$. 


\section{Discussion}

The purpose of the present study was to get the reference value of agility of visually impaired soccer players in accordance with the blind class. Therefore, it was necessary to several methods to evaluate of the agility. Side-step test is generally used in the test to measure the agility. For the visually impaired, in order to adjust the measurement conditions, support rope has been attempted ${ }^{13)}$. The authors hypothesized that there may be a feature of the agility by blind class. WMT method that has been used ${ }^{13)}$, it was added to the PMT method in this study. The cognition is defined as a process for processing information on the basis of reasoning, judgment and memory. Cognitive ability is superior low vision than blind ${ }^{14)}$. PMT method was created in order to clarify the differences in the cognition of space in agility. In doing so, it is possible to obtain the characteristics of agility performance in the visually impaired soccer players.

In side-step test using WMT method, the visually impaired was a high recording than sighted subjects. Moreover, there was no significant difference in blind class, WMT method is considered to have characteristics that reduce the influence of blind class. In side-step test using PMT method, the sighted subjects were significantly higher record than the visually impaired. PMT method has been demonstrated to be associated with spatial cognition in previous research ${ }^{14}$. This study was the result to support the previous research. Interestingly, between the blind class, but there was no significant difference in agility performance using the WMT method, there was a significant difference in the PMT method in agility performance. Takato (2013) reported that blind visual experience of spatial perception by the poor, takes time to acquire the space cognitive ability ${ }^{15}$. Therefore low vision (B2 - B3), it can be considered to be good in agility with spatial cognition. In addition, PMT method can be expected as a method for measuring the agility with spatial cognition.

Sighted subjects can be in the blindfold, agility performance using the PMT method was significantly higher than the agility performance using WMT method. In addition, it is thought that the influence of visual information is low in PMT method. Thus, agility performance also using the PMT method in the visually impaired is likely to improve. The result of this study, agility performance of visually impaired was not never low clause consideration of the failure.

In blind football corresponds to the changing circumstances, such as the position of the ball and players. It inferred that there has been a growing agility performance throughout the competition.

From that there were no significant relationship to the WMT method and PMT method, there are a uniqueness of both methods. Therefore, to measure the characteristics of agility performance of the visually impaired, suggested that using both measurement methods.

\section{Conclusion}

To the authors' knowledge, this is the first study to report of side-step agility test using WMT method and PMT method in visually impaired soccer players. In this study it was possible to obtain the reference value of agility in visually impaired soccer players. The difference of the blind class was suggested agility with spatial cognition. Therefore, low vision was suggested that the superior agility performance with spatial perception than blind.

\section{Acknowledgements}

The authors would like to thank blind soccer teams for their assistance. There was no financial support for this project.

\section{References}

1) Jullien H, Bisch C, Largouet N, Manouvrier C, Carling CJ, Amiard V: Does a short period of lower limb strength training improve performance in field-based tests of running and agility in young professional soccer players? J Strength Cond Res, 2008; 22: 404-411.

2) Sayers A, Sayers BE, Binkley H: Preseason fitness testing in national collegiate athletic association soccer. Strength Cond J, 2008; 30: 70-75.

3) Young WB, Pryor L: Relationship between pre-season anthropometric and fitness measures and indicators of playing performance in elite junior Australian Rules football. J Sci Med Sport, 2007; 10: 110-118.

4) Gambetta V: Speed development for football. Natl Strength Cond Assoc J, 1990; 12: 45-46.

5) Little T, Williams AG: Specificity of acceleration, maxi- 
mum speed, and agility in professional soccer players. J Strength Cond Res, 2005; 19: 76-78.

6) Sugden DA: Problems in Movement Skill Development Columbia, SC: University of South Carolina Press, 1990: $56-57$.

7) Abolfotouh MA, Telmesani A: A study of some psycho-social characteristics of blind and deaf male students in Abha City, Asir Region, Saudi Arabia. Public Health, 1993; 107: 261-269.

8) Portfors-Yeomans CV, Riach CL: Frequency characteristics of postural control of children with and without visual impairment. Dev Med Child Neurol, 1995; 37: 456-463.

9) Sundberg S: Maximal oxygene uptake in relation to age in blind and normal boys and girls. Acta Paediatr Scand, 1982; 71: 603-608.

10) Wolff AF, Hums MA: Sports for athletes with disabilities. In: DePauw KP, Gavron SJ, eds. Disability and Sport. 2nd ed. Champaign: Human Kinetics, 2005:
153-154.

11) Lieberman LJ: Visual impairments. In: Winnick JP, ed. Adapted Physical Education and Sport. 4th ed. Champaign: Human Kinetics, 2011: 233-248.

12) Nakata H: Development of auditory reaction times, using fine and gross motor movements in visually impaired children. In: Kaneko M, ed. Fitness for the Aged, Disabled, and Industrial Worker. Champaign: Human Kinetics, 1990: 148-153.

13) Kakiyama T, Takaishi M: Persons with visual impairments. In: Nakata H, ed. Adapted Physical Activity. Springer-Verlag, 1999: 191-194.

14) Golledge RG, Klatzky RL, Loomis JM: Congnitive mapping and wayfinding by adults without vision. Geojournal Library, 1996; 32: 215-246.

15) Takato J: Assistive technology for mobility and sports activities with visual impairment. Japanese Journal of Adapted Sport Science, 2013; 11: 3-11. 